\begin{tabular}{ll|l} 
Case Reports in & \multicolumn{2}{c}{ Case Rep Gastroenterol 2013;7:522-526 } \\
\cline { 2 - 3 } Gastroenterology & $\begin{array}{l}\text { DOI: 10.1159/000357590 } \\
\text { Published online: December 14, 2013 }\end{array}$ & $\begin{array}{l}\text { ○ 2013 S. Karger AG, Basel } \\
\text { www.karger.com/crg }\end{array}$ \\
\hline $\begin{array}{l}\text { This is an Open Access article licensed under the terms of the Creative Commons } \\
\text { Attribution-NonCommercial 3.0 Unported license (CC BY-NC) (www.karger.com/OA- } \\
\text { license), applicable to the online version of the article only. Distribution permitted for non- } \\
\text { commercial purposes only. }\end{array}$
\end{tabular}

\title{
Rare Cadaveric Finding of a Grossly Enlarged Mucocele Appendix
}

\author{
Anna Farias $^{\mathrm{a}}$ Sarah J. Anderson $^{\mathrm{b}}$ Christine A. Webber ${ }^{\mathrm{c}}$ \\ ${ }^{a}$ Schulich School of Medicine and Dentistry - Windsor Program, Windsor, Ont., \\ ${ }^{\mathrm{b}}$ Department of Community Health Sciences: Medical Education, University of Calgary, \\ Calgary, Alta., and 'Division of Anatomy, Centre for Neurosciences, University of Alberta, \\ Edmonton, Alta., Canada
}

\section{Key Words}

Cadaveric · Histology · Epithelium · Cystadenoma

\begin{abstract}
Appendicular mucoceles are rare clinical findings characterized by dilation and distention of the appendicular lumen by the accumulation of mucus. Their discovery is often incidental from abdominal imaging or more commonly as a secondary surgical finding. In this case study we report the first known recorded case of a cadaveric mucocele appendix discovered during routine dissection of the gastrointestinal system. The recorded cause of death for the 86-year-old female patient was congestive heart failure. We compared the gross anatomy and histology of this enormous appendix with another cadaveric appendix. A pathology report identified the appendicular mucocele as a mucinous cystadenoma.
\end{abstract}

(C) 2013 S. Karger AG, Basel

\section{Introduction}

An appendicular mucocele is defined as a general macroscopic dilation of the appendicular lumen caused by an abnormal accumulation of mucus [1]. It is a rare clinical entity with an incidence rate of $0.2-0.4 \%$ in surgical appendectomy specimens [1-3]. Discovery of an appendicular mucocele can occur in several ways. Under physical examination up to $50 \%$ of patients have a palpable mass in their right lower quadrant coinciding with abdominal pain [4]. Frequently this may lead to the mistaken diagnosis of acute appendicitis, and an appendicular mucocele may be diagnosed upon further imaging or surgery. Appendicular mucocele differs from acute appendicitis in its etiology and chronicity. Furthermore an outer diameter of the appendix $>15 \mathrm{~mm}$ is an appropriate threshold indicative of appendicular 
Farias et al.: Rare Cadaveric Finding of a Grossly Enlarged Mucocele Appendix

mucocele [3]. Approximately 25\% of patients are asymptomatic [5] and discovery may be incidental through abdominal imaging or as a secondary surgical finding for a synchronous malignancy or a variety of other benign conditions [6].

This report describes an abnormally enlarged cadaveric appendix subsequently identified as a mucocele. To date there has been no published report of a cadaveric appendicular mucocele. Of the 608 cadavers dissected in the last 8 years at the University of Alberta, this was our first observation. The patient was an 86-year-old female with a recorded cause of death of congestive heart failure. Routine dissection of the gastrointestinal system revealed an extremely large vermiform appendix. Gross anatomical observation and measurement, histological assessment and a pathologist report diagnosed the abnormality as an appendicular mucocele arising from a mucinous cystadenoma.

\section{Materials and Methods}

Gross anatomical observations of the appendix in situ and in relation to the connecting structures were made. Measurements were taken both with a caliper and a flexible measuring tape. The appendix was then incised and internal measurements and weight of the mucocele were determined. The cadaveric tissues of the mucocele appendix and the normal appendix were processed for preparation of histological slides. The tissue was embalmed up to 10 months previously using traditional methods of the Division of Anatomy at the University of Alberta. Upon discovery of the mucocele appendix, it (and another cadaver's appendix of average size) was embedded in paraffin. The tissues were cryotome-cut into $12-\mu \mathrm{m}$ sections and mounted onto Superfrost Plus glass slides. The sections were deparaffinized and rehydrated in a gradient series of 100, 90, 70, 0\% ethanol washes. The deparaffinized sections were subjected to routine hematoxylin and eosin (H\&E) staining to show overall tissue morphology. Alcian blue stain was used to identify goblet cells and mucous secretions. Briefly, tissue was stained in alcian blue solution (1\% alcian blue in $3 \%$ acetic acid solution, $\mathrm{pH} 2.5$ ) for $30 \mathrm{~min}$ and then counterstained in nuclear fast red solution for 5 min. Both the H\&E- and alcian blue-stained tissues were dehydrated through a gradient of ethanol washes, cleared in xylene and mounted with permount mounting medium.

\section{Results}

Gross anatomical observation of the abnormally large appendix in situ (fig. 1a) determined it presented in the pelvic position (directed towards the pelvic brim) and was untethered (fig. 1a, b). Apart from the unusually large size there were no overt signs of inflammation of the appendix or its surrounding tissue. The mesoappendix did not display any pathology and it contained the appendicular vessels (fig. 1b). The appendicular opening was sealed and appeared slightly intussuscepted into the cecum, and the ileocecal valve was normal (fig. 1e). Measurements indicated that the appendix was $9.7 \mathrm{~cm}$ long with an outer diameter of $3.5 \mathrm{~cm}$ and an outer circumference of $11.1 \mathrm{~cm}$ (fig. 1c, d). Incision and internal examination revealed a white opaque gelatinous substance consistent with that of a mucocele (fig. $1 \mathrm{f}, \mathrm{g}$ ). The wall of the appendix was $0.1 \mathrm{~cm}$ thick and the inner surface appeared smooth. The internal diameter and circumference measured 2.5 and $8.6 \mathrm{~cm}$, respectively. The weight of the mucocele contents (not including appendicular tissue) was $73.1 \mathrm{~g}$. Upon gross observation, the appendicular lumen was thin and stretched with no obvious signs of inflammation. 
Farias et al.: Rare Cadaveric Finding of a Grossly Enlarged Mucocele Appendix

Histological comparison of the mucocele appendix with a normal cadaveric appendix demonstrated that the mucosa and submucosa in the enlarged appendix appeared substantially thinner with less overall organization (fig. 2a). Unlike the normal appendix, where the typical simple columnar epithelium is lined with goblet cells that fold into crypts of Lieberkühn, the mucosal layer of the mucocele appendix was significantly thinner, with simple columnar epithelium containing goblet cells of abnormal morphology and no glandular crypts. The mucocele appendix did not have a discernible lamina propria or muscularis mucosa compared to the control appendicular tissue. Further, the mucocele appendix did not have fat deposits or lymphoid follicles in its submucosa as was prevalent in the healthy tissue. Instead, the submucosa of the abnormal appendix contained collagen-like fibers that are consistent with a previously inflamed tissue. The muscularis externis was still present in the enlarged appendix, but it appeared unorganized and there was no clear distinction between circular and longitudinal smooth muscles as was observed in the normal appendicular tissue. Closer examination of the mucosa of the normal appendix illustrated typical simple columnar epithelium that folded into crypts of Lieberkühn (fig. 2b). The mucocele appendix merely displayed a simple columnar epithelium with no discernible crypts. Alcian blue stain indicated the presence of mucus-secreting goblet cells having secreted mucus into the crypts of Lieberkühn in the healthy appendix (fig. 2c). This alcian blue mucus stain confirmed that the abnormally thin, unfolded epithelia of the mucocele appendix also contained mucus-secreting goblet cells. A pathologist's report confirmed a mucinous cystadenoma (report not shown).

Four types of appendicular mucoceles have been classified primarily based on epithelial structure [1]. In increasing order of severity they are retention cyst, mucosal hyperplasia, mucinous cystadenoma and mucinous cystadenocarcinoma. A retention cyst maintains a normal epithelium with only mild luminal dilation $<2 \mathrm{~cm}$ in diameter. Mucosal hyperplasia has a hyperplastic epithelium but dilation is also mild, this type is $5-25 \%$ of cases. Mucinous cystadenoma, the most common type comprising $63-84 \%$ of cases, is classified by epithelial dysplasia and a marked distention of the lumen at times up to $6 \mathrm{~cm}$. No neoplastic cells are found in the mucus of this type. The fourth type, mucinous cystadenocarcinoma, is classified by its neoplastic epithelium, and distention of the lumen is severe. This class forms $11-20 \%$ of cases [1, 4, 6-9].

This is the first reported case of an aberrantly enlarged cadaveric mucocele appendix. In our case the specific type of appendicular mucocele exhibited by our patient was a mucinous cystadenoma. The setting of the anatomy lab offers an excellent opportunity for students to gain insight into the intricacies of the human body. In this case, the discovery of a mucocele appendix presented a unique opportunity to demonstrate the implications of a rare clinical condition.

\section{Acknowledgment}

This work was completed with support from the Division of Anatomy at the University of Alberta and the Schulich School of Medicine and Dentistry in Windsor, Ontario. We thank Mr. Cregg Webber for photography of the specimens. We would like to express our gratitude to the donors who are the greatest teachers in the anatomy laboratory. 


\begin{tabular}{l|l}
\hline Case Rep Gastroenterol 2013;7:522-526 \\
\hline DOI: 10.1159/000357590 & $\begin{array}{l}\text { C 2013 S. Karger AG, Basel } \\
\text { www.karger.com/crg }\end{array}$ \\
\hline
\end{tabular}

Farias et al.: Rare Cadaveric Finding of a Grossly Enlarged Mucocele Appendix

\section{Disclosure Statement}

The authors affirm that they have no conflicts of interest to disclose.

\section{References}

1 Persaud T, Swan N, Torreggiani WC: Giant mucinous cystadenoma of the appendix. Radiographics 2005;27:553-557.

-2 Madwed D, Mindelzun R, Jeffrey RB: Mucocele of the appendix: imaging findings. AJR Am J Roentgenol 1992;159:69-72.

-3 Lien WC, Huang SP, Chi CL, Liu KL, Lin MT, Lai TI, Liu YP, Wang HP: Appendiceal outer diameter as an indicator for differentiating appendiceal mucocele from appendicitis. Am J Emerg Med 2006;24:801-805.

4 Rampone B, Roviello F, Marrelli D, Pinto E: Giant appendiceal mucocele: report of a case and brief review. World J Gastroenterol 2005;11:4761-4763.

5 Macek D, Jafri SZ, Madrazo BL: Ultrasound case of the day. Mucocele of the appendix. Radiographics 1992;12:1247-1249.

6 Stocchi L, Wolff BG, Larson DR, Harrington JR: Surgical treatment of appendiceal mucocele. Arch Surg 2003;138:585-590.

7 Higa E, Rosai J, Pizzimbono CA, Wise L: Mucosal hyperplasia, mucinous cystadenoma, and mucinous cystadenocarcinoma of the appendix. A re-evaluation of appendiceal 'mucocele'. Cancer 1973;32: $1525-1541$.

8 Demetrashvili Z, Chkhaidze M, Khutsishvili K, Topchishvili G, Javakhishvili T, Pipia I, Qerqadze V: Mucocele of the appendix: case report and review of literature. Int Surg 2012;97:266-269.

-9 Bartlett C, Manoharan M, Jackson A: Mucocele of the appendix - a diagnostic dilemma: a case report. J Med Case Rep 2007;1:183.
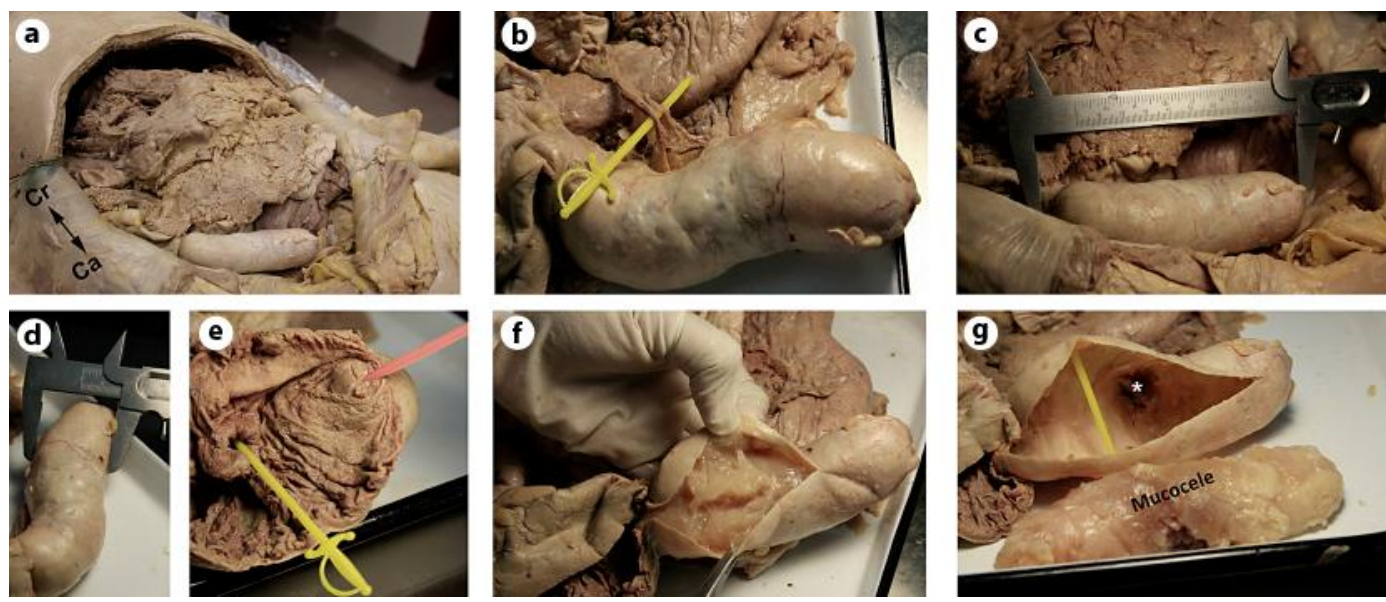

Fig. 1. Anatomical observation of the giant cadaveric mucocele appendix. a The appendix is shown in situ following routine gastrointestinal dissection. b Appendicular vessels in the mesoappendix. c, d Measurement of length and outer diameter of the appendix shown to be 9.7 and $3.5 \mathrm{~cm}$, respectively. e Mucosal plug seen in the appendicular orifice (pink probe). The ileocecal valve is indicated by the yellow probe. $\mathbf{f}$, $\mathbf{g}$ The mucocele removed from the lumen of the appendix. $\mathrm{Cr}=\mathrm{Cranial}$; $\mathrm{Ca}=$ caudal. The asterisk indicates the site of vascularization of the appendix. 
Farias et al.: Rare Cadaveric Finding of a Grossly Enlarged Mucocele Appendix

normal appendix

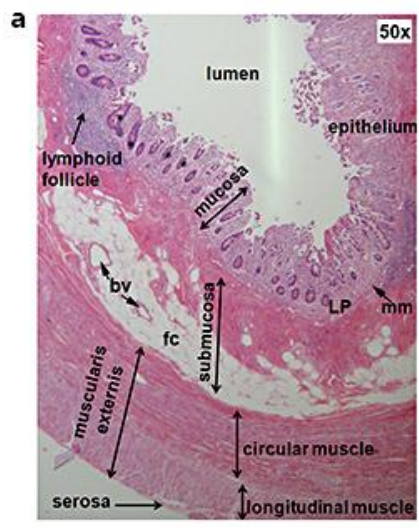

lumen
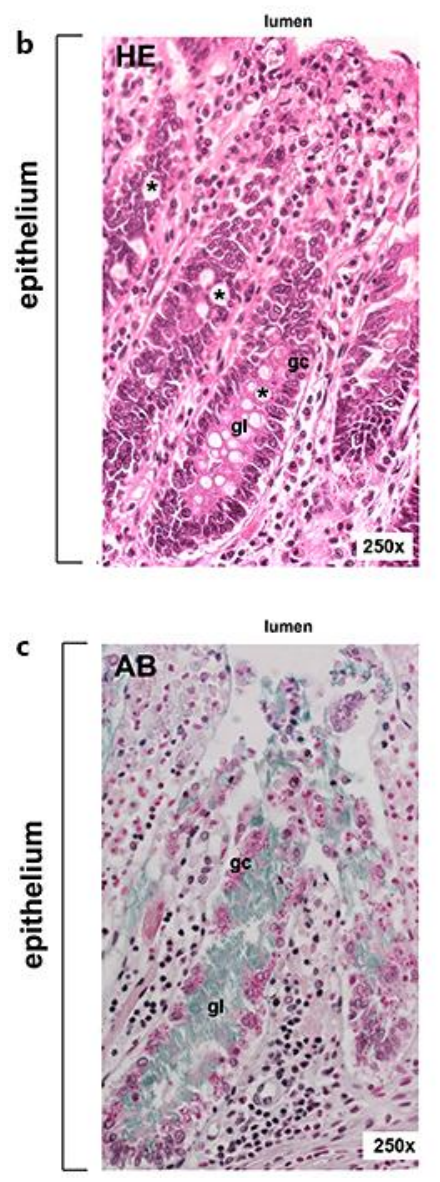

mucocele appendix
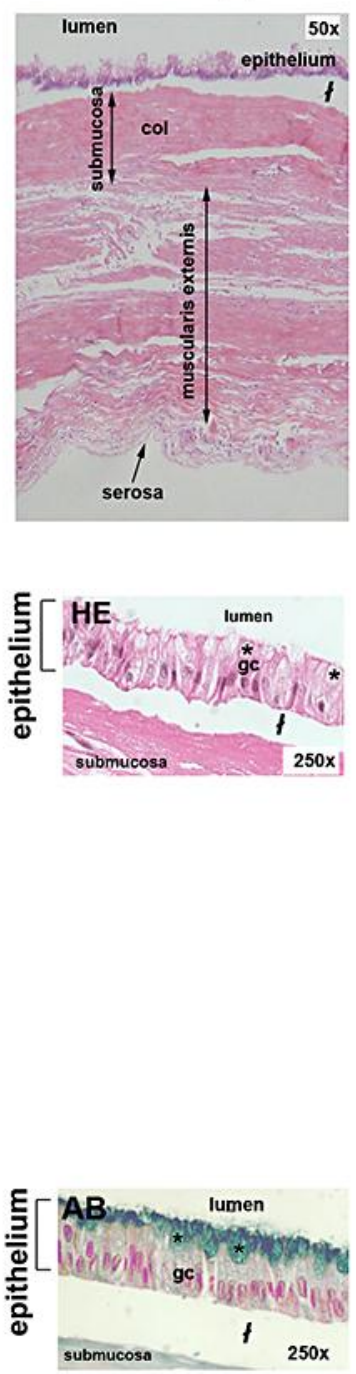

Fig. 2. Histological comparison of a normal and a mucocele cadaveric appendix. The normal cadaveric appendix is shown in the left column and the mucocele appendix is shown on the right. a Cross-section of the H\&E-stained appendices $(\times 50)$. b, c Examination of the epithelial lining of the normal and mucocele appendices using H\&E morphological stain (b) and alcian blue (c) to illustrate the mucus secreted from the goblet cells. $\times 250$. bv = Blood vessel; col = collagen; $\mathrm{fc}=$ fat cells; $\mathrm{gc}=$ goblet cells; $\mathrm{gl}=$ gland; $\mathrm{LP}=$ lamina propria; $\mathrm{mm}=$ muscularis mucosa. The asterisk indicates the mucus-filled vesicle within goblet cell; the $\nmid$ indicates the space artifact of cadaveric tissue. 